\title{
The Application of Network Teaching Platform in Nursing Education
}

\author{
ChunYing $\mathrm{Li}^{1, \mathrm{a}}$, Xian $\mathrm{Qu}^{1, \mathrm{~b}}$ and Jing $\mathrm{Li}^{2, \mathrm{c}^{*}}$ \\ ${ }^{1}$ Department of Physiology, Basic Medical College of Beihua University, Jilin, China \\ ${ }^{2}$ Nursing College of Beihua University, Jilin, China

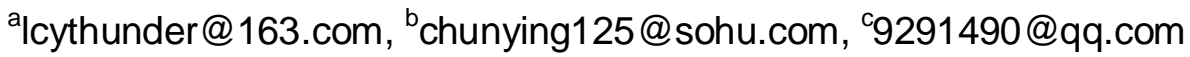 \\ * The Corresponding author
}

Keywords: Component; Network teaching platform; Nursing education; Experiment teaching; Chinese and foreign cooperation; Teaching reform

\begin{abstract}
Objective: It is to explore the application of network teaching platform in nursing education. Take physiology experiment as an example. Methods: Four-year undergraduate international nursing students of 2014 grade were randomly divided into control and experimental groups. The traditional physiology experiment teaching content and teaching methods were used in the control group. Teaching content and teaching methods were reformed in the experimental group. The teaching effect of the two groups was evaluated by the questionnaire, the experimental report writing. Results: The experimental group compared with the control group were significantly improved $(\mathrm{P}<0.05)$ in theoretical results and practical ability. Conclusion: It is to increase the students' initiative and practical ability, to promote the students to observe the problem, to think about and solve problems by outstanding ability of teaching mode in nursing physiology experiments. It is to meet the needs of the development of nursing professional.
\end{abstract}

\section{Introduction}

Network teaching platform is auxiliary teaching platform for teachers and students, which supports interactive communication online for teachers and students. It can provide students with network assisted learning functions, such as browsing selected course corresponding guidance materials, asking online, testing online, discussion-based learning, etc. It can provide teachers with online teaching functions, such as releasing course information, homework, making courseware, answering questions online, testing online, discussion-based learning, and keeping traces of online learning and statistics news and so on. It can expand the teaching space and horizons.

Physiology is an important basic course for nursing profession, which is connected with clinical medicine of disciplines, has a significant role in the whole course system [1]. Physiology is an experimental science, which can improve students' research ability [2] and practice ability. Therefore, physiological experiment teaching is very important to the cultivation of nursing personnel in the new environment.

At present colleges and universities gradually pay attention to the cultivation of nursing talents, but there are still some disadvantages, especially nursing (chinese-foreign cooperation) professional. It belongs to a new professional experience in teaching. Bilingual teaching increased the difficulty of learning. Theory classes and experimental classes of physiology have been cut in the new training scheme. If traditional experiment teaching mode is not improved, it is difficult to cultivate the students' ability. It need for physiology experiment teaching mode reform. We build outstanding application ability training mode of physiology experiment teaching through network teaching platform. And satisfactory results have been achieved, now report as follows. 


\section{Subjects and Methods}

Subjects. Professional nursing four-year undergraduate students (chinese-foreign cooperation) in Beihua University as subjects. The aim is cultivating professional nursing talents with international vision, improving academic background, stronger practice and professional skills. Students were randomly divided into the control group and the experimental group. The control group followed the traditional teaching methods of physiological experiments. The experimental group adopts the experimental teaching content and teaching method after reform.

\section{Methods}

\section{Optimize the Teaching Content.}

The control group followed the traditional teaching methods: Basic technique for mammalian experimentation; Regulation of respiratory movement; Regulation of cardiovascular system. The 40 nursing students were randomly divided into 8 groups, 5 students per group. According to the requirements of teaching outline, each experiment adopt related theory teaching, demonstration teaching, students imitate operation, teachers' guidance, experimental summary, writing experiment reports [4]. The teaching content of the experimental group broke the fixed chapter limits and integrated the contents: Basic technique for Mammalian experimentation; The body's regulation of cardiovascular and respiratory movement (including two parts: experimental design discussion and experimental implementation). 42 nursing students were randomly divided into 8 groups, 5-6 students in each group.

\section{Heuristic Teaching by Application of Network Teaching Platform.}

The traditional experimental teaching, which mainly matches the teaching of theory, belongs to the verification experiment and ignores "How to design the experiment?" "What problem will be occur?" "How to analyze these problems and solve them?", lack of the basic and the active learning ability of training [2]. Designed experiment has a very important role on the students' innovative consciousness, innovative thinking, is an effective way to improve the teaching quality of physiological experiment. But the time of the nursing students exposure to medical experiments is short, who can't finished design experiments independently, so there must be a heuristic teaching. Teacher should setup problem. In order to obtain the required knowledge, the nursing students will read the textbook, the library, the internet, and so on. Discuss with the team and design the project by design report. Design report should include: name of the experiment, the experimental purpose, the experimental equipment, experimental animals, experimental method, experimental steps, expected results and references. Because of the limitations of the time, these interactions were completed in the flexible hours of the network learning platform. It increased flexibility and student learning initiative, breaking the traditional pattern of teaching.

\section{Pay Attention to the Basic Skills of Nursing and the Training of Clinical Skills.}

Practical ability is one of the basic criteria of the applied nursing talent, and we must pay attention to the cultivation of the practice skills of nursing students [5-7]. Physiology experiments including many operations such as the right of grasping animals, ear margin of intravenous anesthesia, nerve and blood vessel separation, endotracheal intubation, artery intubation, intravenous fluids, measuring blood pressure, listen to heart sounds. In traditional teaching, teachers pay attention to the students' imitation and ignore the application of experimental skills. This teaching method focuses on the students' practical ability and develops the students' ability of application. We should strengthen teachers' right guidance for students. Especially experiment for the mammal basic skills training. It is important to make sure that the nursing students are proficient in every part of the experimental procedure.

\section{Assessment of Teaching Effectiveness.}

Traditional examination include attendance and experiment report. The students' experiment report was written after the experiment. Experiment report including title, results, discussion and conclusions. The new methods include attendance, practice skills, and experiment report. 


\section{Statistical Test.}

The data expression shows the mean \pm standard deviation $\left(\bar{x}_{ \pm \mathrm{s}}\right)$, which is analyzed by t-test. P $<0.05$ is statistically significant and all statistical results are by SPSS16.0 for Windows software.

\section{Results}

Comparative Analysis of Experimental Results. The total score was 20, and performance was 5 (according to the performance of the experiment and the overall performance of answering questions). The experiment report was 15. The performance and experiment report and the total result of the experiment were higher in experiment group than control group, and the results were shown in Table 1.

Table 1 Score for Physiology Experiment (score, $\mathrm{x} \pm \mathrm{s}$ )

\begin{tabular}{ccccc}
\hline & Number & $\begin{array}{c}\text { Average } \\
\text { score }\end{array}$ & $\begin{array}{c}\text { Score for } \\
\text { experiment reports }\end{array}$ & Total score \\
Group & & $3.82 \pm 0.50$ & $12.23 \pm 1.18$ & $16.05 \pm 1.25$ \\
$\begin{array}{c}\text { Control } \\
\text { group }\end{array}$ & 40 & & & \\
$\begin{array}{c}\text { Experiment } \\
\text { group }\end{array}$ & 42 & $4.22 \pm 0.51^{\Delta}$ & $13.11 \pm 1.12^{\Delta}$ & $17.33 \pm 1.32^{\Delta}$ \\
\hline
\end{tabular}

Note: Compared with control group, ${ }^{\Delta} \mathrm{P}<0.05$.

The Analysis of Theoretical Scores. We compared the theory test paper of the respiratory system and circulatory system part. A total score is 29. The results show that the experimental teaching method not only improved the experimental effect, but also raised the theory of teaching effect.

Table 2 Score for physiology (SCORE, $\overline{\mathrm{x}} \pm \mathrm{s})$

\begin{tabular}{llllll}
\hline Group & Number & $\begin{array}{l}\text { highest } \\
\text { score }\end{array}$ & $\begin{array}{l}\text { lowest } \\
\text { score }\end{array}$ & $\begin{array}{l}\text { Average } \\
\text { score }\end{array}$ & $\begin{array}{l}\text { passing } \\
\text { rate } \\
(\%)\end{array}$ \\
\hline $\begin{array}{l}\text { Control } \\
\text { group }\end{array}$ & 40 & 24 & 10 & $14.68 \pm 4.65$ & 35 \\
$\begin{array}{l}\text { Experiment } \\
\text { group }\end{array}$ & 42 & 28 & 6 & $18.33 \pm 3.74^{\Delta}$ & 62 \\
\hline
\end{tabular}

Note: Compared with control group, ${ }^{\Delta} \mathrm{P}<0.05$.

\section{Discussion}

Increasing Nursing Students Learning Enthusiasm. Students only can communicate with their teachers during class in traditional class. But due to the amount of time taught, the actual interaction with the students is minimal. Some questions are not answered in time, and students lose interest. Through the application of the network teaching platform, the interaction between the students and the teacher is increased, and the teacher can answer the questions of the students in time. The results of the final test show that the study of the theoretical knowledge related to experimental design is very good, and it is helpful to increase the positivity of the theory learning. 
It is Helpful to Cultivate the Clinical Comprehensive Ability. Nursing has long been a popular major in China and abroad. In order to adapt to the needs of the high level clinical nursing talents, the nursing personnel in chinese-foreign cooperatively-run school mode need to have clinical comprehensive ability. The clinical comprehensive abilities of the nursing students include the ability of clinical practice, clinical thinking and if the team to work together. The results showed that the experimental results were higher than those in the control group. The students are able to combine theoretical knowledge with clinical practice on the basis of "basic theory, basic knowledge and basic skills". It is an important way to train the high level applied nursing personnel.

It is Beneficial to Improve Teachers' Own Quality and Promote the Communication Between Teachers and Students. New teaching mode is not confined to the experiment instruction. There is wide range of topics. The process of analysis and solve the problem need to consult a large number of data. There are a lot of problems to ask teachers. Teacher need timely communicate with students, and be able to correctly guide and help students to solve the problem. It breaks the traditional teaching mode of teacher-centered students, which increases the students' willingness to study and think. At the same time, the communication between teachers and students has been increased effectively, and the new teaching mode has the effect of teaching and learning, which has practical significance to the improvement of teachers' own quality.

It is Helpful to Update the Teaching idea and Improve the Contents and Methods of Nursing Experiment Teaching. This teaching model is different from previous validation experiments, TBL and PBL methods. It is flexible to adopt a variety of teaching methods through the network teaching platform. Teachers carry out heuristics teaching. It is centered on the care of the students and developed student potential. The new teaching mode of physiological experiment not only from education to teaching method, but also from experimental class form to experimental teaching content is more better. New teaching model cultivated clinical practice ability, clinical thinking ability and team cooperation ability of nursing students, which reflects the greater advantages than the traditional teaching.

\section{Acknowledgment}

The 13th five-year plan of the education science in jilin province(GH16078); Beihua University of education teaching and research project.

\section{References}

[1] Guangqian Chen, Meiyu Tan, Dandan Liang. Improved teaching methods to improve physiological teaching [J]. Health professional education, 2014,005:60-61.

[2] Zhengyong Kou, Renjun Wang,Hua Li. Improve the teaching of physiological experiment for students' scientific research ability [J]. Journal of Changchun normal college,2012,12:138$139+114$.

[3] Lihua Yu, Zhanying Lu, Bei Ma. The explore and experience of Physiological experiment design in Eight years students [J]. Basic medicine education,2015,02:137-139.

[4] Haiyun Liu, Yanru Cui, Zhijian He. The application of design experiment in nursing professional physiology experiment was evaluated [J]. China practical care magazine, 2014,30(2):23-25.

[5] Wanqi Huang, Qingzhou Cheng, Dendan Du. Research on the the training system for the use of innovative people in nursing, [J]. Journal of nursing education,2011,26(23):2145-2147.

[6] Songhai Song. Research on the training patterns of undergraduate nursing talent in social needs. [J]. Chinese adult education,2012,(12):132-134.

[7] Hong Chen, Wei Wang, Feng Liang. The practice of cultivating application type nursing talents using the cooperative mode of production and research $[\mathrm{J}]$. Journal of cancer prevention and prevention,2015,22(B11):319-320. 